\title{
Pesquisar para evoluir? PESQUISAR PARA SUPERAR!
}

\author{
Emiko Yoshikawa Egry*
}

\section{Introduzindo o recorte temático}

Admitindo-se a não-neutralidade da ciência e, portanto, da construçáo do saber, torna-se imprescindivel inicialmente, declarar que o trato da temática desta fala será orientado pela visão materialista histórica e dialética de mundo, ou seja, divergirá radicalmente das proposituras funcional-positivistas que têm predominado nas investigaçóes científicas no campo da saúde e da enfermagem no Brasil. A visăo de mundo orientadora de nossa produção cientifica, por sua vez, alberga leis, categorias e pressupostos radicalmente contrários à visăo funcional-positivista.

"A ciência que as universidades ensinam se converte cada vez mais, náo somente num instrumento nas máos dos poderes económico e politico, mas também na cobertura ideologica do sistema capitalista, para o qual o modo de produção dominante do saber cientifico é do saber-mercadoria." (JAPIASSU, 1981:70)

A investigação deve ser entendida fundamentalmente como uma prática social e a ciência como fenômeno processual, como toda a realidade histórica. A compreensão do significado de processo torna-se, portanto, fundamental e no dizer de Demo, a realidade é processual ao conter: a) a historicidade, ou seja, a realidade enquanto parte integrante das vicissitudes da História é o âmago do conceito de processo; b) por ser histórica, a realidade não é perene, nem fixa, imutável, harmoniosa, equilibrada e sempre funcional, ao contrário, a sociedade é conflitiva e em mutação; c) conseqüentemente, a realidade é sempre inacabada, fragmentária como condição de sua existência, no entanto, por não ser somente mutante e conflitiva, há relativa persistência temporal dos fatos históricos, isto é, há ligaçăo entre o perene e o efêmero em contradição dialética; a realidade processual é um vir-a-ser, ou melhor, a ciência não pode ser algo totalmente verdadeiro. (DEMO, 1985:22-3)

Acrescenta Pedro Demo que, "querer captar uma realidade efêmera com conceitos e teorias duradouras ou acabadas é destruir de partida o pensamento através do próprio pensamento. A dialética processual da realidade exigirá, assim, um corpo também processual de categorias, o que quer dizer que toda teoria e metodologia de sua armação não podem ser estatuto fixo, indiscutível, normativo - Enfermeira. Professor Doutor do Departamento de Enfermagem em Saúde Coletiva da Escola de Enfer-
magem da USP. 
absolutamente, mas precariamente válido como é válida uma realidade social". (DEMO, 1985:24)

Dessa forma, as vertentes filosofico-teóricas que buscam a aproximação da realidade com estattetos íxos, imutáveis e normativos, acabam pö se constituìr em limitações da investigação do fenomeno social.

O significado sintético de algumas destas correntes serão expostas a seguir, no sentido de revelar as diferenciações existentes no interior delas e explicitar mais precisamente o caráter limitante de suas concepções.

Referindo-se a Durkheim, Minayo considera que "na prática, a postura positivista advoga uma ciência social desvinculada da posição de classe, dos valores morais e das posições políticas dos cientistas, e acredita nisso. Denomina 'pré-juizos', 'pré-conceitos', 'pré-noções' ao conjunto de valores e opções político-ideológicas do pesquisador, limites a serem transpostos para que ele faça ciência." (MINAYO, 1992:40)

O funcionalismo, como uma das variantes do positivismo sociológico, tem os representantes na antropologia inglesa de Malinowski e Hadcliffe-Brown e na sociologia americana de Merton e Parsons. "Os funcionalistas diferenciam-se de Comte e Durkheim na medida em que negam as leis gerais que regem o funcionamento da sociedade como um todo. Também não reduzem a ciência do social a descriçăo de acontecimentos ou fatos observáveis."(MINAYO, 1992:46)

Dentro do positivismo, o funcionalismo é a corrente de pensamento mais expressiva na área de saude. Em síntese, os princípios fundamentais do funcionalismo săo: "a) as sociedades são totalidades que se constituem como organismos vivos. São compostas por elementos que interagem, inter-relacionam-se e săo interdependentes. Săo sistemas onde cada parte se integra no todo como subsistema, produzindo equilibrio, estabilidade, e sendo passível de ajustes e reajustes. b) For isso mesmo cada sociedade tem seus mecanismos de controle para regular as influências eventuais de elementos externos ou internos que ameacem seu equilíbrio. 'Desvios ' e 'disfunções' fazem parte da concepção do sistema que através dos mecanismos proprios de controle tendem a ser absorvidos, produzindo a integração. Esta é a tendência viva do sistema. c) a integração se consegue pelo consenso através de crenças, valores e normas compartilhados socialmente pelos subsistemas que interagem constantemente e se reforçam mutuamente. d) a conceituação de progresso, de desenvolvimento e de mudanças é adaptativa." (MINAYO, 1992:46-7)

"Os conceitos centrais do funcionalismo (sistema, subsistema, estrutura, função, adaptação, integração, desvio, consenso, etc) são coerentes com o positivismo sociologico, para quem as leis que regem os fenomenos sociais são intemporais, invariáveis e tendentes à estabilidade e à coesão." (MINAYO, 1992:47)

Parsons, cientista norte-americano, é o representante mais relevante dentre os funcionalistas para a área de saúde por ter realizado estudos em seu país sobre a medicina e a relaçăo médico-paciente: (MINAYO, 1992:47)

Minayo revela que a concepção de saúde-doença deste autor mostra claramente esta visăo: "é um estado de perturbação no funcionamento normal do individuo humano total, compreendendo-se o estado do organismo como o sistema biológico e o estado de seus ajustamentos pessoal e social." (MINAYO, 1992:47)

Juan César Garcia, cientista argentino, ao estudar as correntes do pensamento científico na medicina, tece críticas ao funcionalimo parsoniano, na abor- 
dagem do sistema médico. De acordo com Garcia, Parsons ao definir a prática da medicina pela sua finalidade - de curar e prevenir as doenças - limita-se a "descrever como ela funciona e aparece em forma de fenómeno observável, desconhecendo as condições de sua produção e reprodução. Reduz a concepção de doença à noção de 'desvio ' colocando-a no âmbito exclusivo do paciente e do médico. Enfatiza seus respectivos papéis como atores sociais no conjunto da sociedade considerada harmónica e equilibrada. Como conclusão, coloca na maior ou menor suscetibilidade individual às tensões sociais, a responsabilidade da doença. Desconhece os conflitos existentes na sociedade, os interesses que perpassam a medicina como uma produção social e as determinações sociais da saúde-doença." (GARCIA, 1983:104-8)

O marxismo é a corrente de pensamento radicalmente distinta da anterior e se constitue, segundo Garaudy, em síntese metamorfoseada do idealismo de Hegel, da economia política inglesí de Adam Smith e David Ricardo e do socialismo utópico francês de Saint-Simon e Proudhon. (Garaudy, 1967 apud ROCHA, 1987:215)

Para compreender o marxismo é importante elucidar o fenómeno do desenvolvimento social.

Os principios fundamentais do processo de desenvolvimento social podem ser explicados nos termos do materialismo histórico e materialismo dialético, onde o materialismo histórico representa o caminho teórico que aponta a dinámica do real na sociedade e a dialética materialista refere-se ao método de abordagem desse real. (MINAYO, 1992:65)

A opção de abordagem pela dialética materialista não é apenas uma postura ideologica. De acordo com Demo, a metodologia dialética é a mais fecunda para analisar os fenómenos históricos, pois privilegia: "a) a contradição e o conflito, predominando sobre a harmonia e o consenso; b) o fenómeno da transiçăo, da mudança, do vir-a-ser sobre a estabilidade; c) o movimento histórico; d) a totalidade e a unidade dos contrárics". (DEMO, 1985:86-100)

Uma vez que a forma de se aproximar da realidade é totalmente distinta, é imprescindível clarear nessa visão a concepção de saúde-doença que subjaz à produção de conhecimentos e à investigação científica acerca do processo saúdedoença.

Breilh, epidemiólogo equatoriano, concebe o processo saúde-doença como a "síntese do conjunto de determinações que operam numa sociedade concreta, produzindo nos diferentes grupos sociais o aparecimento de riscos ou potencialidades característicos, por sua vez manifestos na forma de perfis ou padrōes de doença ou saúde. Certamente, a qualidade de vida a qual cada grupo sócio-económico está exposto é diferente e, portanto, é igualmente diferente sua exposição a processos de risco que produzem o aparecimento de doenças e formas de morte específicas, assim como seu acesso a processos benéficos ou potencializadores da saúde e da vida". (BREILH, 1986:40)

Ainda, se faz necessário explicar que o recorte temático deste ensaio é no campo da saúde coletiva e, portanto, das investigações cientificas referentes a enfermagem em saúde coletiva. Ao contrário do que muitos imaginam, a "saúde coletiva" não é um neologismo ou mesmo uma tentativa de "modernizaçăo" da "saúde pública", ainda que esta última terminologia seja predominante até hoje e consagrada dentro da produçăo científica da área. 
Jaime Breilh explica que o nome "saúde coletiva" se aplica para designar os novos conteúdos e projeçóes da disciplina que resultou do movimento sanitarista latino-americano, particularmente no Brasil, da corrente da reforma sanitária.

"A Saúde Coletiva surge como um termo vinculado a um esforço de transformação, como opção oposta, como veículo de uma construção alternativa da realidade que é objeto da ação, dos métodos para estudar esta realidade e das formas da "práxis" que se requerem. Enquanto a saúde pública convencional conceitua a saúde-doença empiricamente, reduzindo-a ao plano fenoménico e individualizado da causação etiologica, a saúde coletiva propõe a determinação histórica do processo coletivo de produção de estados de saúde-doença. Enquanto a saúde pública acolhe os métodos empírico-analítico (estrutural-funcionalista), popperiano ou fenomenológico, a saúde coletiva incorpora o método materialista dialético. Enquanto a saúde pública centra sua ação a partir da otica do Estado, com os interesses que este representa nas sociedades capitalistas, a saúde coletiva se coloca como recurso de luta popular e da crítica-renovação estratégicas do 'que-fazer' estatal. Enquanto a saúde pública assume a atitude possivel da consecuçăo de melhorias localizadas e graduais, a saúde coletiva propõe a necessidade de uma ação para a mudança radical." (BREILH, 1990:128-9)

Dentro do campo da saúde coletiva, por coeréncia filosofica, conceitual e metodológica, as investigaçóes científicas vêm lançando mão do método dialético de exposição e as categorias da dialética materialista, até como uma maneira de se contrapor à produção da vertente funcional-positivista. A busca da superação não se encerra na questão de troca de marco metodológico, senão que deve ser atrelada aos movimentos de compreensão histórica da dependência dos países como os nossos, latino-americanos, aos países do bloco capitalista central.

No entanto, para compreender este fato há que se responder à seguinte questáo: Qual é o significado da dependência?

"A dependência é uma situação na qual um certo grupo de países tem sua economia condicionada pelo desenvolvimento e expansão de outra economia a qual a propria economia está submetida. A relaçáo de interdependência entre duas ou mais economias, e entre estas e o comércio mundial, assume a forma de dependência quando alguns países (os dominantes) podem se expandir e se autoimpulsionar, enquanto que outros países (os dependentes) só o podem fazer como reflexo desta expansão, que pode atuar positiva e/ou negativamente sobre o seu desenvolvimento imediato. De qualquer forma, a situação básica de dependência conduz a uma situação global dos países dependentes que os situa em atraso e sob a exploração dos países dominantes." (INFANTE, 1991:191)

"Para compreender o sistema de produção dependente e as formações sócio-económicas que ele conforma, é necessário, pois, vê-lo como parte de um sistema de relações económicas e mundiais baseado no controle monopólico do grande capital, na dominação de uns centros económicos e financeiros sobre outros, no monopólio de uma tecnologia altamente complexa, que condiciona um desenvolvimento desigual e combinado, a nível internacional e nacional." (INFANTE, 1991:208)

A realidade destes países so pode ser analisada no marco de um processo de produção e reprodução dependente. Ao contrário, reduzir esta análise ao entendimento desta realidade como um produto do subdesenvovimento, é assi- 
milar o obscurecimento ideológico disfarçado de ciência. (INFANTE, 1991:208)

Nesta relação, o sistema economico dependente "é obrigado a competir em condiçסes de desigualdade com o capital internacional no interior de suas fronteiras, impondo uma relação de super-exploração da força de trabalho em seu interior para dividir o excedente económico gerado entre os dominadores internos e externos". (INFANTE, 1991:208)

Entendida a questão da dependência resta indagar: Por que buscar a compreensão do recorte epistemológico da saúde coletiva?

Na visão materialista-histórica e dialética esta compreensão é buscada pela necessidade de uma investigação em enfermagem que possibilite a aproximação da realidade visando a sua transformação. Em outros termos, ao abraçar esta concepção, $o$ investigador assume a obrigação de encontrar os caminhos adequados para a transformação do objeto investigado, ou seja, de luta pela preservação e desenvolvimento da essência humana, onde ele cumpre um trabalho no qual seu esforço se plasma na construção de idéias e ações humanizantes que buscam novas explicaçóes teóricas e metodológicas, numa crítíca permanente às técnicas dominantes. (GRANDA, 1991).

O caráter principal da investigação em enfermagem em saúde coletiva é, portanto, o năo-contemplativo e não-universalizador, ao contrário, temporal e interventivo da transformação da realidade objetiva.

É importante destacar, também, que por ser o processo saúde-doença socialmente determinado, é essencialmente um fenomeno social que não se pode apreender isolada e sectariamente como se pudesse se constituir em um "setor" isolado da sociedade, ou seja, um fenomeno desarticulado do todo social. Ao contrário, abrir uma cunha de aproximação através da categoria "totalidade" permitirá o entendimento das relaçóes entre o geral, o particular e o singular dos fenomenos sociais.

Entáo, neste momento cabe aclarar, mesmo que de forma suscinta, o conceito de "totalidade dialética" a que se reporta esta categoria, fundamental para a investigação em enfermagem em saúde coletiva.

O conceito de totalidade implica uma complexidade em que cada fenomeno só pode vir a ser compreendido como um momento definido em relaçăo a si e em relação aos outros fenomenos. Isto não significa que se deva conhecer todos os fenomenos igual e indistintamente. Significa que o fenomeno referido so se ilumina quando referido à sua essência, ou seja, aqueles elementos que definem a sua própria natureza, no seu processo de produçáo. A totalidade so é apreensível através das partes e das relações entre essas partes. Ainda, a totalidade não é um todo já-feito, não é uma simples harmonia, pois ela não existe acabada, mas é sempre um processo de totalizaçăo a partir das relaçóes de produçăo e de suas contradições. Na totalidade, cada realidade e cada esfera dela é uma totalidade de determinações, de contradições atuais ou superadas. A realidade só pode ser conhecida na sua totalidade concreta quando se conhece sua dimensáo social e histórica, compreendendo a unidade dialética da estrutura e superestrutura onde o homem é reconhecido como sujeito da práxis. (CURY, 1989:34-8)

Diante de tudo isto, pesquisar para superar, na concepçáo dialética de superação, é não desconsiderar o caráter positivo da realidade anterior, compreendendo-o como aquilo que permaneceu do anterior e que integra a nova qualidade. 
Com esta nova concepçăo, o "pesquisar para superar" é um desafio para todos os pesquisadores no campo da saúde coletiva e particularmente da enfermagem. Para enfrentá-lo, dois momentos importantes de reflexão devem ser destacados para se caminhar em direção ao horizonte da transformação qualitativa da produção científica: o que superar e como superar?

\section{Construindo o conhecimento para superar (o que superar?)}

Em primeiro lugar, superar a pretensa isenção político-ideológica das pesquisas em saúde e em enfermagem.

A enfermeira e professora Raimunda Medeiros Germano ao realizar extenso e crítico estudo sobre a produção cientifica divulgada através da Revista Brasileira de Enfermagem da Associação Brasileira de Enfermagem, principal veículo de divulgação da produção científica da enfermagem no Brasil, em meados da década passada, manifestava como conclusão de sua obra, exatamente a base ideologizada do conteúdo das publicações. As conclusões foram geradas através da análise crítica de seus conteúdos onde foi destacado que:

a) os trabalhos retratam a concepção do social e da sociedade de forma abstrata, alijados do conteúdo histórico e dos conflitos sociais;

b) o Estado é visualizado como entidade protetora e paternal e nåo como mantenedora da dominação; cismo;

c) a produção revela a educação e a enfermagem impregnadas pelo tecni-

d) a concepção de saúde está encerrada no campo biológico do humano. (GERMANO, 1985:105)

A autora destaca a percepção de uma enfermagem fundamentalmente conservadora em sua prática social por não mencionar sequer a sua existência numa sociedade concreta, brasileira, regida pelo modo de produçáo capitalista e, vale dizer, periférico e dependente. Se não há explicitação, não haverá problematização e, portanto, não haverá o desencadeamento do processo de reflexão crítica. Finaliza com a grave denúncia de que "os intelectuais da enfermagem desempenham o papel de verdadeiros intelectuais orgânicos das classes dominantes (reportando-se a Gramsci - nota do autor)" (GERMANO, 1985:111)

Infelizmente, quase uma década após esta obra, o quadro da produçáo cientifica da enfermagem pouco mudou em termos da clareza do pesquisador enquanto um produtor social do conhecimento e o processo de investigar enquanto parte de um fenómeno social historicamente determinado. A alienação do produtor de seu lugar social na produção cientifica não é ainda uma realidade superada.

Na enfermagem em saúde coletiva, o início da década de setenta corresponde à época em que as produções cientificas descortinam possibilidades de desalienação.

A crítica aos marcos teóricos capacita o pesquisador à dupla negação dialética: a) a negação da teoria constituída, seja porque a retifica, ou porque descobre novos caminhos metodológicos e por isso retifica também os elementos técnicos; b) a negaçáo dialética do conhecimento ideologizado inicial para passar a conhecedor mais profundo dessa realidade que quer mudar, transformando-o a si próprio. (GRANDA, 1991:45) 
Superar esta contradição significa então abandonar radical, cmbora paulatinamente, a metodologia funcional-positivista que tem como princípio a norma, o universal e o harmónico, por serem estas reveladoras e ao mesmo tempo consagradoras do projeto politico das classes doininantes.

A segunda superaçăo refere-se a falsa dicotomia do modelo clínico e do modelo epidemiologico, ou do individual e do coletivo, para visualizar o fenómeno saúde-doença como uma relação de contradiçáo dialética do indivíduocoletivo.

Para compreender isto é necessário, primeiramente, esclarecer o significado de "coletivo". A epidemiologia enquanto uma sub-disciplina da saúde coletiva esclarece a questão posta, ou seja, do modelo slínico versus o modelo epidemiológico.

De acordo com Breilh, a "clínica é um conjunto de conceitos, métodos e formas de atıação prática aplicados ao conhecimento e à transformação do processo saúde-doença na dimensão individual. Seu objeto de trabalho é, conseqüentemente, o conjunto de condições finalmente identificadas no indivíduo como manifestações de uma série complexa de determinações que operam nos processos supra-individuais. Devido a natureza individual de seu objeto, a clínica adota as ciências naturais como suporte teórico e instrumental. A clínica prioriza as ciências físicas e biológicas e recorre às ciências sociais e filosoficas (especialmente psicologia, semiologia e administração) de forma muito limitada. $O$ método que a clínica utiliza é intensivo no sentido de realizar estudo minucioso e exaustivo dos processos individuais de caráter orgânico-funcional e psíquico. Correspondendo à natureza individual de seu objeto e ao caráter intensivo de seu métơdo, as formas de atuação clínica são igualmente singulares, sejam estas do tipo preventivo primário (isto $\epsilon$, prevenção etiológica imediata), sejam do tipo corretivo ou reabilitador". (BREILH, 1991:39-40)

Por outro lado, a "epidemiologia deve ser um conjunto de conceitos, métodos e formas de atuaçáo prática que se aplicam ao conhecimento e à transformação do processo saúde-doença, em sua dimensão coletiva ou social. Seu objeto de trabalho acha-se delineado pelos processos que, no dominio social geral ou das classes e frações sociais especiais, determinam a produção de condições específicas de saúde e doença. O corpo teórico e instrumental em que se apóia a epidemiologia corresponde principalmente às ciências sociais e às ciências naturais em sua expressão supra individual. A epidemiologia recorre às disciplinas da física e da biologia de forma limitada. (...) A epidemiologia situa, coerentemente, seu nivel de ação transformadora no social, na problemática da saúde que se dá em consequência dos processos de deterioraçáo ocorridos no trabalho e consumo das classes sociais e frações, processos esses vinculados à reprodução geral da estrutura capitalista e à condiçőes políticas e culturais que dela derivam". (BREILH, 1991:40)

A relação entre o biológico e o social no processo saúde-doença é explicado mais claramente por Asa Cristina Laurell, pesquisadora da Universidade Autônoma Metropolitana de Xochimilco, da Cidade do México. Ao enunciar a concepção saúde-doença da coletividade como sendo o "modo específico pelo qual ocorre no grupo o processo biológico de desgaste e reproduçáo", destaca como "momentos particulares a presença de um funcionamento biológico diferente com conseqüências para o desenvolvimento regular das atividades cotidia- 
nas, isto é, o surgimento da doença". (LAURELL, 1983:151)

Desta forma, o processo saúde-doença manifesta-se de distintas maneiras sendo visivel, por exemplo, através de indicadores como a expectativa de vida, as condições nutricionais, ou as taxas de morbi-mortalidade. Mesmo em se tratando do processo saúde-doença de um grupo, a sua expressão é social na medida em que não é possivel focalizar a normalidade biologica do homem desvinculada do momento historico, exemplificado no fato de que é impossível determinar a duração normal do ciclo vital, por ele ser variável em épocas distintas. (LAURELL, 1983:152)

"A relação entre o processo de saúde-doença coletiva e do indivíduo fica, então, estabelecida, porque o processo saúde-doença coletiva determina as características básicas sobre os quais assenta-se a variação biológica individual." (LAURELL, 1983:153)

\section{Investigando a realidade para transformá-la (como superar)}

"Há duas dimensões na politicidade da ciência que devem ser reconhecidas na análise epistemológica para a compreensão do problema do método: uma politicidade externa que se fixa no conteúdo e projeção classista dos vínculos do trabalho cientifico com a sociedade e o poder, o que poderia referir-se à relação entre o geral e o particular, e uma politicidade interna que se encontra na construção do modo de pensar científico e que se expressa na própria configuração das categorias e explicaçóes que a ciência incorpora. Tende-se a considerar a primeira forma, separando-a da segunda e descuidando da congruência interna do quefazer cientifico. Dessa falsa dicotomia surgem posturas equivocadas sobre o papel da ciencia frente às classes subalternas, reduzindo-o ao problema do controle da ciência e seu uso, negligenciando-se a transformação interna das disciplinas." (BREILH, 1990:149)

"A corrente marxista está transformando a politicidade da Medicina Social nessas duas dimensões: primeiro, uma articulação distinta do trabalho acadêmico e técnico com o povo, mediante a superação deste paternalismo verticalista para contribuir na formulação de um projeto histórico global das classes subordinadas, projeto que busca ampliar e consolidar os espaços democráticos de construção de um poder popular na gestão, que pretende resgatar a autarquia dos países nas decisões de saúde e que se projeta como instrumento de canalização das necessidades mais profundas das massas, incorporando a participação dos grupos dominados como sujeitos do processo de conhecimento. Em segundo lugar, uma reconfiguração teórico-métodológica que se estrutura em torno do eixo materialista dialético e permite refletir a realidade objetivamente, em seu movimento e relaçōes, e não no contato externo de coisas ou ' fatores de doença' ', transformando os diagnósticos, para entender como a 'totalidade' (sócio-económica) com suas contradições determina o movimento, as condições e os limites do desenvolvimento da ' parte' (padrões gerais de saúde), e como, por sua vez, as condições especificas da 'parte' (saúde) contribuem, dentro desses limites, para a configuração e dinamismo do objeto-problema do que-fazer, segundo o momento e o lugar que se tenha selecionado para atuar. (BREILH, 1990:150)

A contribuição do marxismo ao avanço do saber em saúde, pode ser destacada, atraves da: 
a) construção de uma cultura de transformação desalienada, favorecendo o compromisso com as classes sociais subalternas;

b) consolidação de um saber que busca transformar os objetos do conhecimento, porisso mesmo crítico e não contemplativo. Superação das bases empiricistas e neopositivistas pela abertura de caminhos para compreender a relação dialética entre o biológico e o social, entre os eventos individuais e os coletivos, entre a necessidade e o acaso, tranformando substancialmente o princípio da causalidade;

c) profunda revisão do método científico mediante a articulação dinâmica dos métodos dedutivo e indutivo, produzindo mudança metodológica no processo investigativo, relacionando dialeticamente a quantidade e a qualidade e o teórico e o prático;

d) interpretação objetiva da realidade desvelando o caráter ideológico das práticas e das políticas;

e) transformação na teoria do conhecimento que possibilitou um estudo objetivo dos determinantes e características do saber enquanto problemas de formação e desenvolvimento do pensamento científico, e ainda, repercussões profundas na pedagogia e processo ensino-aprendizagem. (BREILH, 1990:152-3)

\section{Em síntese - os horizontes de superaçáo.}

O horizonte de superação enquanto lugar, espaço e processo, constitui-se também em uma totalidade no qual o proprio caminhar para o seu alcance revelará as contradições dialéticas entre a qualidade presente e a qualidade futura da estrutura geral da produção de conhecimentos em enfermagem em saúde coletiva.

A qualidade nova que pode ser antevista, ou seja, o horizonte, é o da compreensão de que a investigação em enfermagem em saúde coletiva é um fenómeno social articulado ao trabalho da enfermagem enquanto prática social, desenvolvida numa realidade concreta e histórica. Caminhar para este horizonte deve contemplar, de ora em diante, com muito mais firmeza:

- o estudo das tendências do desenvolvimento social, de forma insepa-rável do movimento interventivo de captar e interpretar a realidade objetiva objeto da investigação - considerada sempre como totalidade-parte e, ao mesmo tempo, contenedora de partes desta totalidade-parte. Explicando melhor, o exame minucioso da totalidade-parte significa buscar não somente as categorias que revelam o seu interior, mas também a articulação destas com os polos existentes na totalidade imediatamente superior. Equivale dizer que todo objeto a ser investigado encontra-se em relação dialética com a estruturação de uma dada sociedade, a configuração do setor saúde, o trabalho em saúde e em enfermagem, consideradas as distinções temporais (históricas) e espaciais (micro e macro regiões).

- o estudo aprofundado dos determinantes do processo de produção do conhecimento em enfermagem em saúde coletiva, reportados à compreensão histórica e dinâmica da produção científica. Isto significa que a própria produção e o seu produtor necessitam permanentemente de revisão crítica de seu processo de trabalho - finalidade, meio/instrumento e objeto - sem o que corre-se o risco de reiterar, perene e cristalizadamente, a resposta mecânica ao projeto político das classes dominantes.

- a disseminação da investigação cientifica enquanto uma ação insepa-- 
rável das demais ações cotidianas dos trabalhadores, em todos os âmbitos do trabalho de enfermagem, para possibilitar a geração dos conhecimentos necessários ao desvelamento das características particulares e singulares de cada processo de trabalho da enfermagem e, ao mesmo tempo, buscar através da dialetização, a superação das contradições do geral, particular e singular, do teórico-prático, do fenomeno e da essência, entre outras. Ainda, buscar a permanente produção dos meios e intrumentos necessários para a intervenção em saúde coletiva para a transformação da qualidade de vida e de saúde das populações, por meio de ações técriica-cientificas, políticamente competentes e socialmente comprometidas.

Finalizando, creio ter colocado, nesta explanação, algumas questões centrais que vêm sendo objeto de reflexão e debate dentro do Departamento de Enfermagem em Saúde Coletiva e do Núcleo de Apoio às Atividades de Cultura e Extensão Univeristária: Integração Docente Assistencial em Saúde Coletiva (NACE:IDASC).

Vale mencionar que a nossa própria produção científica tem sido, na maior parte das vezes, participativa e coletiva, coerentemente com o referencial teórico-metodológico adotado. Aproveito a oportunidade para, neste momento, expressar os meus agradecimentos aos grupos mencionados, por esta construção conjunta.

Enquanto trabalhadores da área da saúde coletiva, nossa contribuição nos últimcs anos tem sido, entre outras, a da produção de conhecimentos através de investigaçóes científicas o:ientadas pelo materialismo histórico e dialético. Com a finalidade de divulgá-los junto aos que desejam aprofundar seus conhecimentos na temática, desfilo, após as referências bibliográficas, alguns trabalhos produzidos mais recentemente, com base no referencial supra-citado.

\section{REFERENCIAS BIBLIOGRÁFICAS}

BREILH, J. Epidemiologia: economia, política e saúde. São Paulo, UNESP-HUCITEC, 1991.

BREILH, J. Reprodução social e investigaçăo em saúde coletiva: construção do pensamento e debate. In: COSTA, D. C. (org.) Epidemiologia: teoria e objeto. Såo Paulo, HUCITEC-ABRASCO, 1990. p.12865.

BREILH, J.; GRANDA, E. Investigação da saúde na sociedade: guia pedagógico sobre um novo enfoque do método epidemiológico. São Paulo, Instituto de Saúde-ABRASCO, 1986.

CURY, C. R. J. Educação e contradição. Săo Paulo, Cortez, 1989.

DEMO, P. Metodologia cientffica em ciencias sociais. São Paulo, Atlas, 1985.

GARCIA, J. P. Medicina e sociedade: as correntes de pensamento no campo da saude. In: NUNES, E. D. (org.) Medicina social: aspectos históricos e teóricos. São Paulo, Global, 1983. p.95-132.

GERMANO, R. M. Educação e ideologia da enfermagem no Brasil. $2^{2}$ ed. São Paulo, Cortez, 1985.

GRANDA, E. Compromiso social de la investigación en salud. Invest Educ. Enf., v. 9, n. 1, p. 33-50, 1991.

INFANTE, N. B. de; ALVAREZ, L. Sociedad y salud Cali, Formas Precisas, 1991.

JAPIASSU, H. Questões epistemológicas. Rio de Janeiro, Imago, 1981.

LAURELL, A. C. A saúde-doença como processo social. In: NUNES, E. D. (org.) Medicina social: aspectos históricos e teoricos. Săo Paulo, Global, 1983. p.133-58 
MINAYO, M. C. S. O desafio do conhecimento: pesquisa qualitativa em saúde. Såo Paulo, HUCITECABRASCO, 1992.

ROCHA, S. M. M.; SILVA, G. B. da. Linhas filos6ficas e ideologicas na pesquisa em enfermagem no Brasil. Rev. Bras. Enf., v. 40, n² 4, p. 214-21, out/dez, 1987.

\section{LEITURAS RECOMENDADAS}

BERTOLOZZI, M. R. Pacientes com tuberculose pulmonar no Munictpio de Taboão da Serra: perfil e representaçōes sobre ạ assistencia prestada nas unidades básicas de saude. Săo Paulo, 1991. 213 p. Dissertaçâo (Mestrado). Faculdade de Saúde Pública, Universidade de Săo Paulo.

CASTELLANOS, B. E. P.; SHIMA, H.; BERTOLOZZI, M. R.; EGRY, E. Y. Desafios da enfermagem brasileira no contexto da América Latina para a década de 90. Saúde em Debate, n. 34, p. 72-6, 1992.

EGRY,E. Y. Sistematizaçåo da assistência de enfermagem em saúde coletiva orientada pelo materialismo histórico e dialético: em busca da unicidade entre o saber e o fazer. In: SEMANA WANDA DE AGUIAR HORTA, 3, Såo Paulo, 1989. Anais. Såo Paulo, Escola de Enfermagem da USP, 1990. p. 97-110.

EGRY, E. Y.; FONSECA, R. M. G. S. da; SHIMA, H.; SALUM, M. J. L. Processo de integração docente assistencial: espaço e movimento possíveis na construçăo do saber em saúde coletiva. Rev. Bras. Enf., v. 45, n. 1, p. 9-14, 1992.

EGRY, E. Y.; FONSECA, R. M. G. S. da; BERTOLOZZI, M. R. Método de assistência de enfermagem em saude coletiva orientado pelo materialismo histórico e dialético: o entendimento do processo para aplicaçăo do instrumento. In: CONGRESSO BRASILEIRO DE ENFERMAGEM, 42, Natal, 1990. Anais. Associação Brasileira de Enfermagem, Seção R. N., 1990 (no prelo).

EGRY, E. Y. et al. Integraçăo Docente Assistencial como referencial teorico-metodológico para o ensino e. a pesquisa da assistencia em enfermagem em saúde coletiva. In: UNIVERSIDADE DE SĀO PAULO. Integração Docente Assistencial. Săo Paulo, Escola de Enfermagem da USP, 1992. p. 75-155.

FONSECA, R. M. G. S. da. Mulher, reprodução biologica e classe social: a compreensão do nexo coesivo através do estudo dialético do perfil reprodutivo biologico de mulheres atendidas nas Unidades Básicas de Saúde. Såo Paulo, 1990. 336 p. Tese (Doutorado) - Escola de Enfermagem, Universidade de Săo । Paulo.

OLIVEIRA, M. A. de C. A reprodução biologica em uma sociedade de classes: estudo dialético das representaçőes de um conjunto de enfermeiras. São Paulo, 1988. 242 p. Dissertação (Mestrado) - Escola de Enfermagem, Universidade de São Paulo.

QUEIRÓZ, V. M.; EGRY, E. Y. Bases metodologicas para a assistencia de enfermagem fundamentada no materialismo histórico e dialético. Rev. Bras. Enf., v. 41, n. 1, p. 26-33, 1988. 